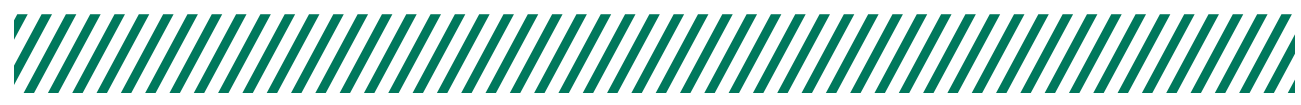

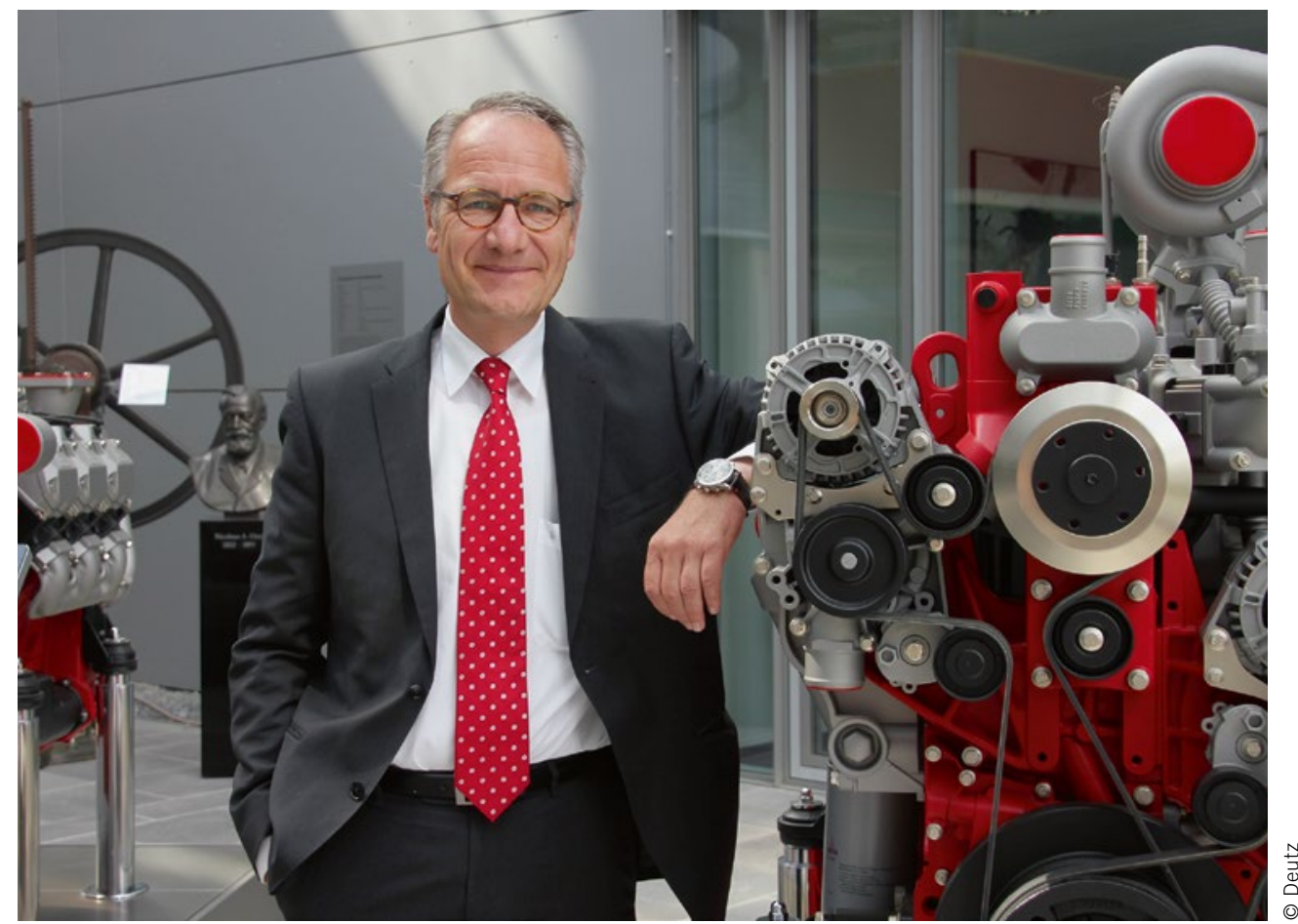

Dr. Markus Schwaderlapp Leiter Forschung und Entwicklung der Deutz AG

\section{Dekarbonisierung in der Landwirtschaft}

In der Landwirtschaft sind leistungsstarke Motoren und hohe Energiespeicherkapazitäten gefragt. Daher war und ist der Diesel der Antrieb der Wahl. So ermöglicht ein 590-l-Diesel-Tank in einem schweren Traktor etwa $10 \mathrm{~h}$ Pflugarbeiten bei hoher Last auf dem Feld. Zum Vergleich: Ein reiner Elektroantrieb müsste - auf Basis aktuell marktüblicher Batterietechnik - mit einem Akkupaket von etwa 45001 Volumen und 12 t Gewicht ausgestattet werden, um die gleiche Arbeit verrichten zu können.

Dennoch ist $\mathrm{CO}_{2}$-Reduzierung (Dekarbonisierung) in der Landwirtschaft möglich. Durch den Einsatz alternativer Kraftstoffe und Elektrifizierung von Nebenantrieben kann die Effizienz von Verbrennungsmotoren nochmals deutlich gesteigert und perspektivisch sogar ein $\mathrm{CO}_{2}$-neutraler Betrieb erreicht werden. Bei der Wahl des Kraftstoffs reicht das Spektrum von Gas und Biokraftstoffen über hydrierte Pflanzenöle (HVOs) aus recycelten Pflanzenölen oder Abfallfetten bis zu dieselidentischen E-Fuels auf Basis von regenerativem Strom.

Im Rahmen eines Forschungsprojekts wurde zum Beispiel mit einem erdgasbetriebenen 3,6-1-Motor in einem Traktor von Same Deutz-Fahr eine $\mathrm{CO}_{2}$-Reduzierung von bis zu $24 \%$ erzielt. Bei Einsatz von Biogas ist der Betrieb sogar $\mathrm{CO}_{2}$-neutral. Biokraftstoffe oder HVOs werden aus nachwachsenden, nachhaltig produzierten Biorohstoffen gewonnen und ermöglichen einen weitgehend geschlossenen $\mathrm{CO}_{2}$-Kreislauf, weil die Pflanzen bei ihrem Wachstum $\mathrm{CO}_{2}$ aus der Luft entnehmen. Dem gleichen Prinzip folgen auch E-Fuels, wo im Herstellungsprozess ebenfalls $\mathrm{CO}_{2}$ aus der Atmosphäre gebunden wird. Der Motorenbetrieb mit beispielsweise synthetischem DieselKraftstoff ist dabei besonders komfortabel, da dieser mit fossilem Diesel in jedem Verhältnis misch- und einsetzbar ist. Entsprechende Freigaben für Serienmotoren sind bereits vorhanden.

Ein weiterer Ansatzpunkt ist der Einsatz von Wasserstoff in Verbrennungsmotoren. Das Münchner Startup Keyou betreibt dazu mit einem 7,8-1-Sechszylinder bereits einen vielversprechenden Prototyp. In Sachen Kraftstoff werden wir somit zukünftig eine weitere Diversifizierung beobachten. Als Hersteller ist es dabei wichtig, frühzeitig die richtigen Lösungen anzubieten - der Markt wird letztlich entscheiden, welche Konzepte sich durchsetzen.

Gleichzeitig wird die Evolution des Verbrennungsmotors durch die Elektrifizierung des gesamten Antriebssystems unterstützt. Im ersten Schritt bedeutet das eine milde Hybridisierung auf Basis eines 48-V-Systems. Hier bieten sich insbesondere in der Landwirtschaft vielfältige Möglichkeiten, um Nebenantriebe elektrisch zu betreiben. So wird der Verbrennungsmotor entlastet, was die Effizienz des Gesamtsystems verbessert und die Betriebskosten verringert. Alternative Kraftstoffe und Elektrifizierung sind vor allem auch in der Kombination konkrete Schritte zur effektiven Dekarbonisierung. 